\title{
CONF--950476-10
}

UCRL-JC-121326

PREPRINT

\section{Ultra-Intense, Short Pulse Laser-Plasma Interactions with Applications to the Fast Ignitor}

\author{
S. C. Wilks \\ W. L. Kruer \\ P. E. Young \\ J. Hammer \\ M. Tabak
}

This paper was prepared for submittal to the 12th International Conference on Laser Interaction

\& Related Plasma Phenomena

Osaka, Japan

April 24-28, 1995

April 1995

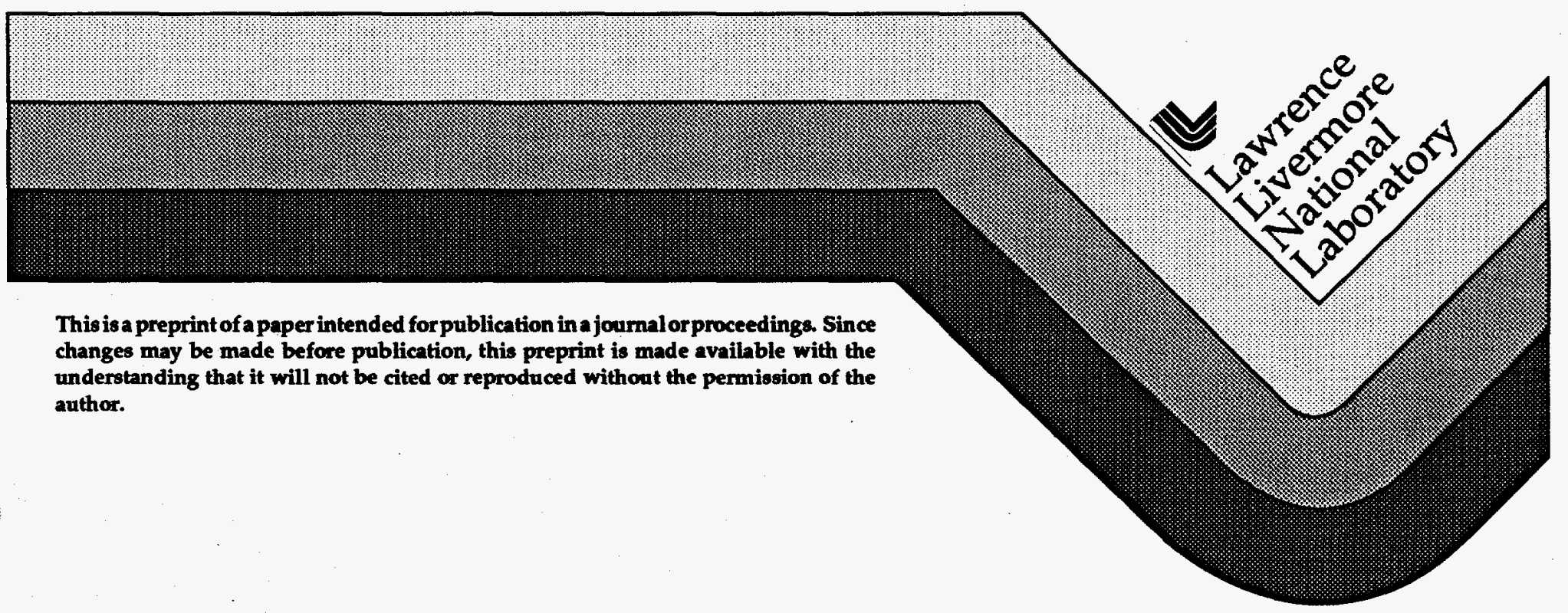




\section{DISCLAIMER}

This document was prepared as an account of work sponsored by an agency of the United States Government. Neither the United States Government nor the University of California nor any of their employees, makes any warranty, express or implied, or assumes any legal liability or responsibility for the accuracy, completeness, or usefulness of any information, apparatus, product, or process disclosed, or represents that its use would not infringe privately owned rights. Reference herein to any specific commercial product, process, or service by trade name, trademark, manufacturer, or otherwise, does not necessarily constitute or imply its endorsement, recommendation, or favoring by the United States Government or the University of California. The views and opinions of authors expressed herein do not necessarily state or reflect those of the United States Government or the University of California, and shall not be used for advertising or product endorsement purposes. 


\section{DISCLAIMER}

Portions of this document may be illegible in electronic image products. Images are produced from the best available original document. 


\title{
Ultra-Intense, Short Pulse Laser-Plasma Interactions with Applications to the Fast Ignitor
}

\author{
S. C. Wilks, W. L. Kruer, P. E. Young, J. Hammer, and M. Tabak \\ $X$-Division and Dept. of Physics \\ Lawrence Livermore National Laboratory, Livermore, CA 94550
}

\begin{abstract}
Due to the advent of chirped pulse amplification (CPA) as an efficient means of creating ultra-high intensity laser light ( $\mathrm{I}>5 \times 10^{17} \mathrm{~W} / \mathrm{cm}^{2}$ ) in puilses less than a few picoseconds, new ideas for achieving ignition and gain in DT targets with less than 1 megajoule of input energy are currently being pursued. Two types of powerful lasers are employed in this scheme: (1) channeling beams and (2) ignition beams. The current state of laser-plasma interactions relating to this fusion scheme will be discussed. In particular, plasma physics issues in the ultra-intense regime are crucial to the success of this scheme. We compare simulation and experimental results in this highly nonlinear regime.
\end{abstract}

\section{INTRODUCTION}

The fast ignitor (FI) fusion concept ${ }^{1}$ is a promising new method of potentially obtaining dramatically higher gain than conventional inertial confinement fusion (ICF), for a given amount of input energy. More importantly, this high gain may be achieved at significantly lower driver energy $(\sim 100 \mathrm{~kJ})$ than is theoretically possible with conventional isobaric models of ICF 2 . The recent availability of ultra-intense, short pulse lasers allows for the delivery of a considerable amount of energy to a compressed core in a short time, $(\sim 10 \mathrm{psec})$ thus allowing for higher gains at lower input energies. A detailed outline of the FI is given in reference ${ }^{1}$. In this paper, we concentrate on the plasma physics issues that arise in this scheme.

A brief description of the fast ignitor will now be given, First, a standard (directly driven) implosion is created, in the usual way. This is envisioned to be a high density compression, such as that obtained at $\mathrm{Osaka}^{3}$, in which they achieved $600 \mathrm{~g} / \mathrm{cc}$. It is important to note that since the FI does not rely on shock timing for ignition, mix and associated Rayleigh-Taylor instabilities are not a concern. Next, a $100-p s e c, 10^{18} \mathrm{~W} / \mathrm{cm}^{2}$ laser is directed at this imploded pellet, creating a channel evacuated of plasma through the underdense portions of the corona. This laser also pushes on the critical surface. In fact, although the critical surface starts out at about $200 \mu \mathrm{m}$ from the center of the compressed core, it is thought that this laser can push the critical surface to about $150 \mu \mathrm{m}$ from the center of the core. The third step in the process is the firing of a second, more intense $\left(\sim 10^{20} \mathrm{~W} / \mathrm{cm}^{2}\right)$, shorter $(\sim 10 \mathrm{psec})$ laser which is sent down the channel created by the first laser pulse. When this intense laser interacts with the dense plasma at 




FIGURE 1. Schematic of the four steps involved in the fast ignitor fusion concept.

the end of the channel, a substantial number of $\mathrm{MeV}$ electrons are then generated. These electrons transport to the core, and initiate a burn in the compressed DT, thus yielding many times the total input energy. The entire process is summarized in Fig. 1. As seen in the above description, this scheme relies heavily on laserplasma interaction in a relatively unexplored regime of parameter space; namely ultra-intense, ultra-short laser plasma interactions with both underdense and overdense plasmas.

\section{CHANNELING LASER ISSUES}

We begin with the channeling laser issues. The first item is the competition between filamentation and self-focusing of the laser beam in this underdense portion of the corona. Clearly, filamentation will be detrimental to channel creation, whereas self-focusing will help to form a channel. This has been studied both theoretically and experimentally. Early experiments by $P$. Young 4 using a $100 \mathrm{psec}, 10^{15} \mathrm{~W} / \mathrm{cm}^{2}$ pulse shot into a $1 / 10-1 / 4 \mathrm{n}_{\mathrm{cr}}$ plasma with parabolic profile created by pre-exploding a $\mathrm{CH}$ foil, showed that a channel forms early, but does not exist past the peak of the density profile. Subsequent simulations, such as that shown in Fig. 2a, showed that the laser was actually filamenting, then "spraying" apart. This spreading of the laser beam was later confirmed by experiments by $\mathrm{P}$. Young 5 ; the results are shown in Fig $2 \mathrm{~b}$. Additional simulations and experiments predicted that if the pulse was longer, or equivalently, if the intensity was higher, that channel formation would be possible. This has since been observed, and details regarding the exact relation between various laser and plasma parameters that allow channel formation can be found in Ref. 6. 
Once the channel has formed, it is important that the laser push the critical surface closer to the core. Hole boring is a key element of the FI, and an important question is how deep the laser can "drill" or push into the overdense plasma. Hole boring has been observed in simulations with laser intensities of $10^{19} \mathrm{~W} / \mathrm{cm}^{2}$, pushing a density step of $4 \mathrm{n}_{\mathrm{cr}}$ approximately $3 \mu \mathrm{m}^{7}$.
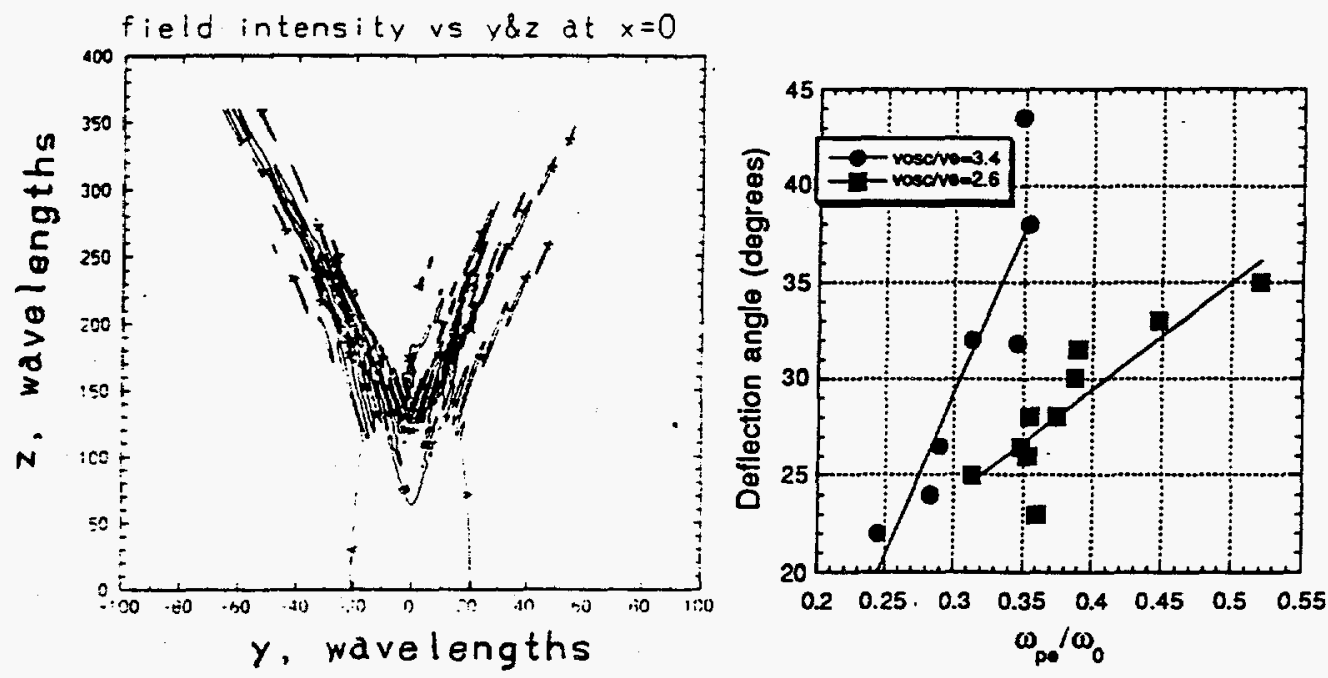

Figure 2. (a) Field intensity from a 2-D hydro simulation at $t=50 \mathrm{psec}$. The laser propagates from bottom to top. Note channeling of laser in lower portion of plot. Subsequent filamentation results in laser beam spray at an angle. (b) Experimentally measured ngular beam deflection as a function plasma density for two intensities.
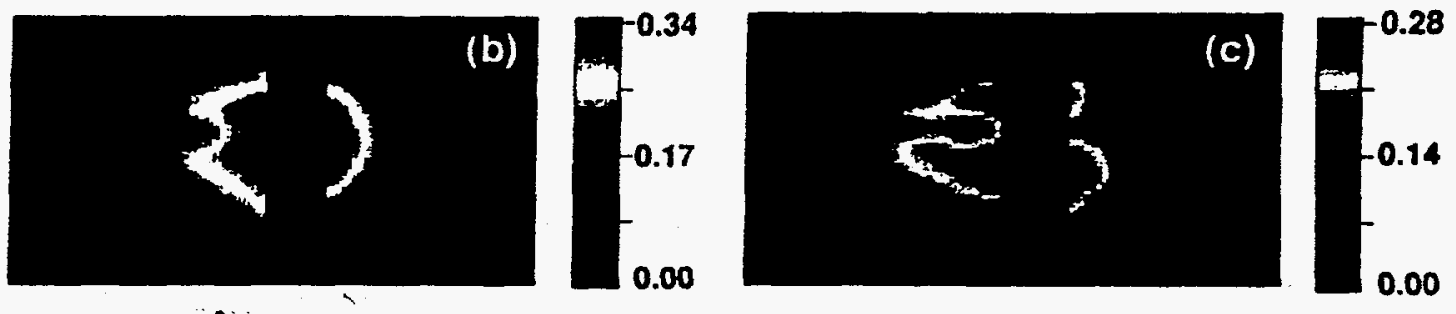

Figure 3. Experimental data showing channel formation at (a) $50 \mathrm{psec}$ and (b) $400 \mathrm{psec}$, for an $1 \lambda^{2}=10^{16}$ W/cm ${ }^{2}$ laser pulse traversing a parabolic density profile plasma with peak density $n=1 / 4 n_{\mathrm{cr}}$. The laser propagates from left to right in these enhanced density interferograms.

By balancing the momentum flux of the ion mass flow with the light pressure, it is found that the critical surface recedes at a velocity given by. 8

$$
\frac{\mathcal{V}_{f}}{c}=\sqrt{\frac{n_{c r}}{n_{p}} \frac{Z_{m}}{M} \frac{I \lambda^{2}}{2.74 \times 10^{18}}}
$$


where $n_{p} / n_{c r}$ is the density at the end of the channel $M$ is ion mass, $m$ is the electron mass, $Z$ is the charge state of the ions, $I$ is the intensity and $\lambda$ is the wavelength of the incident laser. Clearly, the reflected light will be red-shifted, since the surface it is reflecting off of is receding. This has been experimentally observed by Kalashnikov, Nickles et. al. ${ }^{9}$ Thus, the ability of the laser to push the critical surface at least in one regime has been demonstrated.

\section{IGNITOR BEAM ISSUES}

We now discuss a few of the laser plasma physics issues concerned with the second laser puise, the so-called ignitor pulse. The first issue is maintaining the integrity of the ignitor pulse as it propagates down the channel. Even with channel creation, there will most likely be a small amount of residual plasma in the channel, as shown in Fig. 4. Even plasma densities of $10^{-3} \mathrm{n}_{\mathrm{cr}}$ in the channel can cause detrimental effects to the ignitor pulse, since the intensity is of order $10^{20} \mathrm{~W} / \mathrm{cm}^{2}$ and the growth rate of instabilities such as relativistic filamentation and Stimulated Raman Scattering (both back and forward) depend on the density and intensity. For example since the power threshold relativistic filamentation ${ }^{10}$ is given by $P_{c r} \sim 16\left(n / n_{c r}\right) G W$, a 10 pSec pulse with a $10 \mu \mathrm{m}$ FWHM width in a $10^{-3} n_{c r}$ plasma is well above threshold. This may ultimately cause the beam to "spray" similar to what happens in ponderomotive filamentation as discussed above.

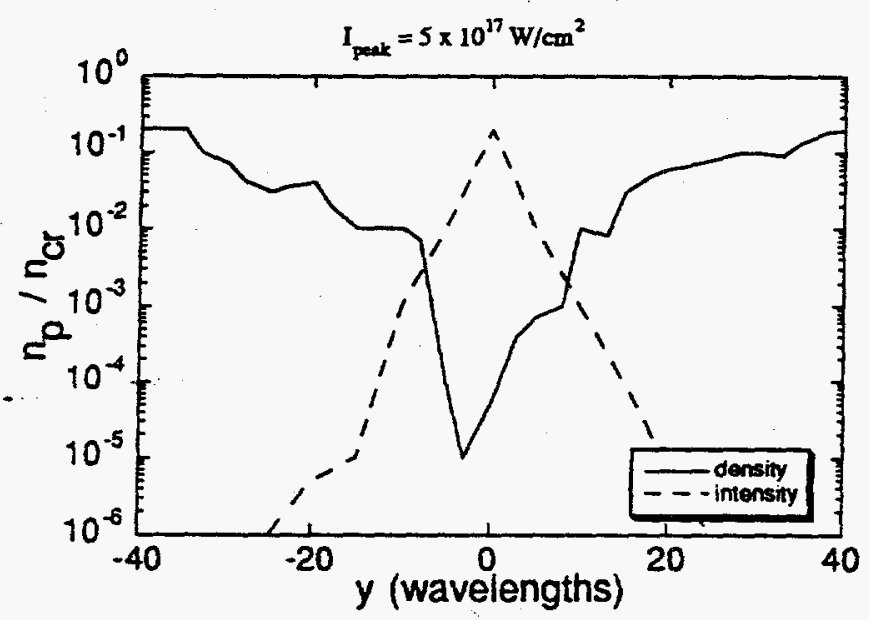

Figure 4. Transverse cut near peak of density profile from a hydro simulation, showing deep channel formation (solid line) due to intense laser (dotted line), with peak intensity $1 \lambda^{2}=10^{17} \mathrm{~W} / \mathrm{cm}^{2}$.

In addition, SRS forward scatter ${ }^{11}$ has been shown to cause transverse beam break-up in ultra-short (100 femtoseconds) intense laser pulses. Let us briefly consider the effects of SRS backscatter on the ignitor pulse in detail. Previous studies of $1 \mathrm{pSec}$ pulses with intensities $>10^{17} \mathrm{~W} / \mathrm{cm}^{2}$ have shown that considerable SRS backscatter is possible. ${ }^{12}$ This is an important concern for the 
ignitor pulse, in that a substantial fraction of the ignitor energy $(-1 / 2)$ could easily be scattered back out of the hole. Many recent experiments with picosecond, intense lasers have noticed a broadening of the backscattered spectrum. 13,14 Through PIC simulation studies, we have attributed this to the following mechanism. Previously ${ }^{12}$, we have shown that when the product of the growth rates and the pulses length $\left(\tau_{p}\right)$ is such that

$$
\gamma \tau_{p} \cong \frac{1}{2} \frac{\mathcal{V}_{o s c}}{c} \sqrt{\frac{\omega_{p}}{\omega_{0}}} \tau_{p} \sim 15
$$

substantial SRS occurs. This results not only in backscattered light, but also in a large fraction $(-50 \%)$ of the plasma electrons heated to an effective temperature of $\sim 18 \mathrm{keV}$. The back half of the pulse can not only scatter off the cooler electrons near the initial temperature of the plasma (at $-5 \mathrm{keV}$ ), but also Compton Scatter off of the high temperature component of the plasma. This two temperature plasma distribution has been seen in simulations, such as that shown in Fig. 5.
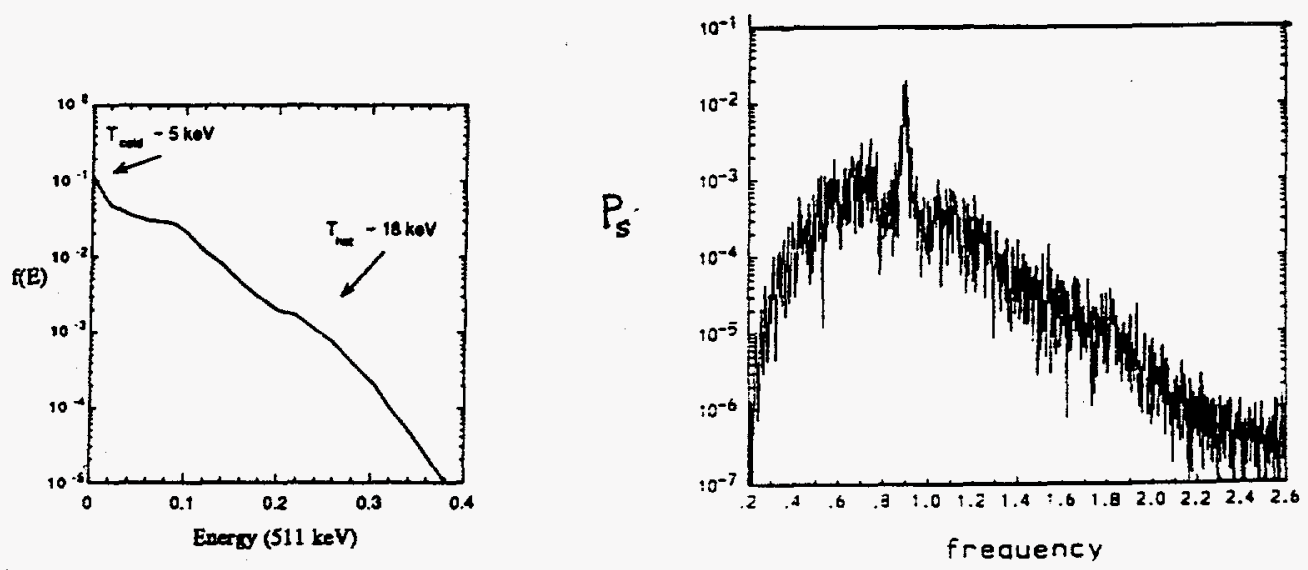

Figure 5. (a.) electron distribution function of plasma electrons, after intense laser $(1=$ $10^{18} \mathrm{~W} / \mathrm{cm}^{2}$ ) has passed by, showing cold component ( $\mathrm{Te} \sim 5 \mathrm{keV}$ ) and hot component $\left(T_{h} \sim 18 \mathrm{keV}\right)$. (c) Resulting backscatter spectra, showing broad feature associated with Compton Scattering, and sharp peak associated with SRS off cold component.

This is a good example of how unexpected phenomena can occur, and add difficulties otherwise not foreseen in this new regime of ultra-intense laser plasma interactions. It is currently thought that although these parametric instabilities may play a role early on, in the $10 \mathrm{psec}$ pulse, that they will in fact be transitory, thus allowing for propagation of the ignitor pulse down the channel.

Assuming that the ignitor pulse has propagated to the steepened critical surface, we now turn our attention to the generation of hot electrons that will ultimately be deposited into the compressed core. Two things are important in this step; 1.) significant absorption into the hot electrons must be achieved, and 2.) these electrons must have the correct energy $(\sim 1 \mathrm{MeV})$ to have a range in the compressed core corresponding to a $3.5 \mathrm{MeV}$ alpha particle. Theory and 
simulation 7,8 have indicated that for $1 \lambda^{2}>5 \times 10^{17} \mathrm{~W} \mu \mathrm{m} / \mathrm{cm}^{2}$, the energy of electrons produced at a steepened critical surface is roughly twice the pondermotive potential associated with the laser. This fact, coupled with the fact that 1-2 MeV electrons have the same range as $3.5 \mathrm{MeV}$ alphas, dictates that $\sim 10^{19}-10^{20} \mathrm{Wum} / \mathrm{cm}^{2}$ should be used for the ignitor pulse. The second point is that PIC simulations see extremely good absorption into hot electrons, even at very high $\left(\sim 100 \mathrm{n}_{\mathrm{Cr}}\right)$ densities, of 2-dimensional effects are taken into account. 15 Experiments are only now beginning to access this regime, but initial results look promising. ${ }^{16}$ Theoretical work by Yang, et al ${ }^{17}$, that discusses various absorption mechanisms, is beginning to unravel the complex mechanisms governing absorption of ultra-intense pulses on critical surfaces. Another issue has recently been brought up, that may have consequences for the ignitor pulse. Self-induced transparency 18 may allow the ignitor puise to propagate past the critical surface, and thus generate energetic electrons even closer to the core.

The final step, propagation of hot electrons to the compressed core has been studied by Glinsky, Mason, Hammer and Tabak, ${ }^{19}$, and the reader is referred to this paper for details. One interesting note is that the B-fields seen in the overdense plasma published in previous work ${ }^{7,8}$ have also been seen in Ref. 19 , and may help guide the hot electrons to the core.

\section{CONCLUSIONS}

In conclusion, we have reviewed some of the important plasma physics issues relevant to the Fast Ignitor fusion concept. In particular, channeling beam issues such as channel creation and hole-boring have been shown to be feasible both through simulation and experimentally. Secondly, ignitor beam issues, such as the efficient generation of $\mathrm{MeV}$ electrons at a steepened critical surface. It is encouraging that many of the important aspects of the fast ignitor have been observed in experiment. However, these are individual experiments which test only one specific aspect of the FI at a time. As the expertise in laser building progresses, a system capable of doing an integrated experiment will emerge, thus allowing for a true test of this novel fusion concept.

\section{REFERENCES}

1. M. Tabak, J. Hammer, M. Glinsky, W. L. Kruer, S. C. Wilks, J. Woodworth, E. M. Campbell, and M. Perry, Phys. Plasma, 11626 (1994).

2. J. Meyer-er-Vehn, Nucl. Fusion 22, 561 (1982).

3. H. Azechi, T. Jitsano, T. Kanabe, M. Katayons, K. Mima, N. Miyanaga, M. Naki, S. Naki, H. Nakaishi, M. Nakatsuka, A. Nishiguchi, P.A. Norrays, Y. Setsuhara, M. Takagi, M. Yamanaka, and C. Yamanaka, Laser Part. Beams, 9, 2 (1991).

4. P. E. Young, Phys. Fluids B 3, 2331 (1991). 
5. S. C. Wilks, P. E. Young, J. Hammer, M. Tabak, and W. L. Kruer, Phys. Rev. Lett. 73, 2994 (1994).

6. P. E. Young, J. Hammer, W. L. Kruer and S. C. Wilks, Phys. Rev. Letter, to be published (1995).

7. S. C. Wilks, W. L. Kruer, M. Tabak, and A. B. Langdon, Phys. Rev. Lett, 69, 1383 (1993).

8. S. C. Wilks, Phys. Fluids B, 5, 2603 (1993).

9. Kalashnikov, P. E. Nickles, Th. Schlegel, M. Schnuere, F. Billardt, I. Will, W. Sandner, and N.N. Demchenko, Phys. Rev. Lett., 73, 260 (1994).

10. C. E. Max, J. Arons, and A. B. Langdon, Phys. Rev. Lett, 33, 2091 (1974); W. B. Mori, C. Joshi, J. M. Dawson, D. W. Forsiund and J. M. Kindel, Phys. Rev Lett. 60, 1298 (1988); A. Borisov, et.al. Phys. Rev. A, 45, 5830 (1992).

11. T. Antonsen and P. Mora, Phys. Rev. Lett, 69, 2204 (1992); W. B. Mori, C. Decker, D. E. Hinkel, T. Katsouleas, Phys. Rev. Lett., 72, 1482 (1994).

12. S. C. Wilks, W. L. Kruer, E. A. Williams, P. Amendt, D. Eder, Phys. Plasmas, 2274 (1995).

13. C. Coverdale, Phd Thesis (1995).

14. A. Ting, K. M. Krushelnick, A. Fisher, C. Manka, H. R. Burris, NRL Report No. 6790-95-7667 (1995).

15. W. L. Kruer and S. C. Wilks, LIRPP proceedings, Monterey Meeting, 105, editor G. Miley, (1994).

16. C. Darrow, D. Klem, private communications; D. Price, private communication.

17. T. - Y. B. Yang, W. L. Kruer, R. M. More, and A. B. Langdon, to be published Phys. Plasmas (1995).

18. G. Bonnaud, to be published in Phys. Rev. Letts. (1995).

19. M. E. Glinsky, R. J. Mason, and M. Tabak, Bull. Am. Phys. Soc. 38, 2080 (1993).

*This work was performed under the auspices of the U.S. Department of Energy by Lawrence Livermore National Laboratory under contract No. W-7405-Eng-48. 